\title{
Fibromyalgia syndrome: preventive, social and economic aspects
}

\section{Gli aspetti preventivi, sociali ed economici della sindrome fibromialgica}

\begin{abstract}
L. Altomonte ${ }^{1}$, F. Atzeni ${ }^{2}$, G. Leardini ${ }^{3}$, A. Marsico ${ }^{4}$, R. Gorla ${ }^{5}$, R. Casale ${ }^{6}$, G. Cassisi ${ }^{7}$, S. Stisi $^{8}$, F. Salaffi ${ }^{9}$, F. Marinangeli ${ }^{10}$, M.A. Giamberardino ${ }^{11}$, M. Di Franco ${ }^{12}$, G. Biasi ${ }^{13}$, G. Arioli ${ }^{14}$, A. Alciati ${ }^{15}$, F. Ceccherelli ${ }^{16}$, L. Bazzichi ${ }^{17}$, R. Carignola ${ }^{18}$, M. Cazzola ${ }^{19}$, R. Torta ${ }^{20}$, D. Buskila ${ }^{21}$, M. Spath ${ }^{22}$, R.H. Gracely ${ }^{23}$, P. Sarzi-Puttini' ${ }^{2}$

${ }^{1}$ UOC of Rheumatology Hospital S. Eugenio, Rome, Italy; ${ }^{2}$ Rheumatology Unit, L. Sacco University Hospital, Milan, Italy; ${ }^{3}$ Rheumatology Unit, SS Giovanni e Paolo Hospital, Venice, Italy; ${ }^{4}$ Rheumatology Unit, Hospital of Taranto, Taranto, Italy; ${ }^{5}$ Rheumatology and Clinical Immunology, Spedali Civili and University of Brescia, Italy; ${ }^{6}$ Department of Clinical Neurophysiology and Pain Rehabilitation Unit, Foundation Salvatore Maugeri, IRCCS, Scientific Institute of Montescano, Montescano (PV), Italy; ${ }^{7}$ Rheumatology Branch, Specialist Outpatients' Department, Belluno, Italy; ${ }^{8}$ Rheumatology Unit, "G. Rummo” Hospital, Benevento, Italy; ${ }^{9}$ Department of Rheumatology, Polytechnic University of the Marche Region, Ancona, Italy; ${ }^{10}$ Department of Anesthesiology and Pain Medicine, L'Aquila University, L'Aquila, Italy; ${ }^{11}$ Ce.S.I. "G. D'Annunzio" Foundation, Department of Medicine and Science of Aging, "G. D'Annunzio", University of Chieti , Italy; ${ }^{12}$ Chair of Rheumatology, University la Sapienza Rome, Rome, Italy; ${ }^{13}$ Unit of Rheumatology, University of Siena, Siena, Italy; ${ }^{14}$ Division of Rehabilitative Medicine and Rheumatology, General Hospital of Pieve di Coriano (Mantua), Italy; ${ }^{15}$ Department of Psychiatry, L. Sacco University Hospital, Milan, Italy;

${ }^{16} \mathrm{IOV}$ (Veneto Cancer Institute), IRCCS, Department of Pharmacology and Anesthesiology, University of Padua, Italy; ${ }^{17}$ Department of Internal Medicine, Division of Rheumatology, S. Chiara Hospital, University of Pisa, Italy; ${ }^{18}$ S.C.D.U. Internal Medicine I, Department of Clinical and Biological Science, University of Turin, Italy; ${ }^{19}$ Unit of Rehabilitative Medicine "Hospital of Circolo", Saronno (VA),

Italy; ${ }^{20}$ Department of Neuroscience, University of Turin, A.S.O. San Giovanni Battista of Turin, Turin, Italy; ${ }^{2 l}$ Department of Medicine H, Soroka Medical Center and Faculty of Health Sciences, Ben Gurion University, Beer Sheva, Israel; ${ }^{22}$ Friedrich-Baur-Institute,

University of Munich, Munich, Germany; ${ }^{23}$ Department of Medicine, University of Michigan Health System, Ann Arbor, Michigan USA
\end{abstract}

Competing interests: none declared

\section{RIASSUNTO}

Diversi sono i problemi associati al concetto di prevenzione primaria nella FM. I criteri diagnostici o classificativi non sono universalmente accettati e risulta difficile stabilire l'esordio e la durata della malattia. Nel caso della FM, la prevenzione primaria potrebbe essere intensa come il trattamento del dolore acuto o dei disturbi affettivi data la mancanza di test di laboratorio o strumentali specifici predittivi per lo sviluppo della FM. L'obiettivo della prevenzione secondaria è nei pazienti ancora sintomatici la diagnosi e il trattmento precoce. Lo screening consente nei pazienti che possono sviluppare la FM, di identificare la malattia latente o i fattori di rischio quali i TPs, il Fibromyalgia Impact Questionnaire (FIQ), l'intensità e la sede del dolore, l'astenia e disturbi del sonno. Per prevenzione terziaria si intende trattare la malattia al fine ridurne la disabilità e le possibili complicanze. Gli obiettivi terapeutici sono il controllo del dolore e miglioramento della funzionalità attraverso trattamenti farmacologici e non. I pazienti affetti da FM determinano un utilizzano notevole delle risorse sanitarie, e conseguentemente un aumento della spesa sanitaria. Il grado di disabilità e il numero delle malattie associate determina un marcato aumento dei costi. La diagnosi precoce permettebbe di ridurre i costi e il numero delle indagini, consentendo un risparmio effettivo da parte del sistema sanitario nazionale. Tuttavia, l'intervento sociale è strettamente correlato con il livello socio-economico della popolazione generale e la legislazione del paese nel quale il paziente risiede.

\section{INTRODUCTION}

Fitsid ibromyalgia (FM) is a central pain syndrome that is characterized, in part, by specific tender

Corresponding author:

Piercarlo Sarzi-Puttini, MD

Director of Rheumatology Unit

L. Sacco Hospital, Milan, Italy

E-mail: sarzi@tiscali.it points (TPs) in the musculoskeletal system which are exceptionally sensitive to pressure. Pain, specifically characterized as hyperalgesia and allodynia, is the cardinal symptom of FM; however, most patients also experience additional symptoms such as debilitating fatigue, disrupted or nonrestorative sleep, functional bowel disturbances, and a variety of neuropsychiatric problems, including cognitive dysfunction, anxiety and depressive symptoms (1). 
Women are the most affected and the disease has a familial connection that is linked to the genetic variance of serotonin, dopamine and catecholamine intra-cerebral system (2). The physical symptoms of FM often express themselves in conjunction with psychological conditions, which causes a reduction in the individual capacity to tolerate stressors (3).

Despite some criticism, the diagnosis for FM is based on the American College of Rheumatology (ACR) 1990 criteria, which require a specific history (widespread pain lasting more than three months, sleep disturbance, debilitating fatigue, paresthesia) and tenderness to light touch $\left(4 \mathrm{~kg} / \mathrm{cm}^{2}\right)$ of at least 11 of 18 specific tender points (4).

\section{PREVENTION OF FIBROMYALGIA}

FM has a general population prevalence of 2-4 \%, is more common among females than males (5), and results from a combination of genetic aspects and stressful events. Prevention may occur in clinical, community or population settings and is often classified into primary, secondary and tertiary types.

\section{Primary prevention of fibromyalgia}

In general, primary prevention includes measures that help avoid onset of a given health care problem $(6,7)$. In the case of FM, primary prevention might include immediate care of acute pain episodes and of somatoform disturbances. At present, specific laboratory or instrumental markers of FM do not exist, and many open questions remain concerning the concept of primary prevention in FM.

Over time, several issues have arisen with the existing diagnostic or classification criteria: a) criteria are not likely to be applied uniformly by untrained assessors; b) patients may have the requisite TPs and yet not have FM; and c) TPs and widespread pain do not capture the essence of FM; this disorder is known for its multiple and varying symptoms, which include fatigue, sleep disturbance and cognitive dysfunction, predominantly. The road of onset and development of FM can be long and winding. In fact, there are a variety of different clinical histories that can describe the FM road: a female FM patient may develop headaches and dysmenorrhea in her $2^{\text {nd }}$ or $3^{\text {rd }}$ decade of life and present with widespread pain and tenderness later in life; FM can also start after a stressful event
Table I - Predictors for chronicity (fibromyalgia) in recurrent widespread pain.

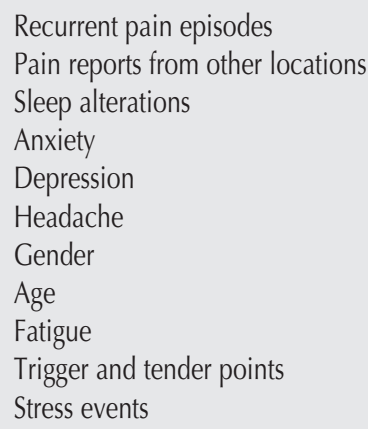

(e.g., physical or psychological trauma); or it can begin with localized pain (e.g., neck or low-back pain) and develop further through pain amplification $(8,9)$.

One major problem with primary prevention stems from the simple fact that no markers of disease exists; a variety of clinical symptoms can be present at onset and chronic widespread pain may or may not develop into FM as defined by the 1990 ACR criteria.

In conclusion, the goal of primary prevention is to reduce the incidence of FM in a population that may have a diathesis toward developing FM but has not presented with symptoms. This can be accomplished through diet and exercise, prevention and cure of trauma, prevention and cure of anxiety and depression, and finally, immunization against viruses and bacteria (Table I).

\section{Secondary prevention of fibromyalgia}

The U.S. Guide of Clinical Preventive Services (Ed. 1996) describes secondary prevention measures as those that "identify and treat asymptomatic persons who have already developed risk factors or preclinical disease but in whom the condition is not clinically apparent".

The purpose of screening is to identify an unrecognized disease or risk factor (10). In general, screening tests include history (e.g., asking if a patient smokes), physical examination (e.g., blood pressure determination), lab tests (e.g., serum cholesterol level) and procedures (e.g., colonscopy). Such tests are not intended to be diagnostic and should not be performed unless the patient and the clinician are committed to further investigation and treatment of abnormal results.

For patients in whom FM is suspected, preventive strategies should be performed to identify risk factors or predictors of chronicity. 
In a clinical setting special attention should be paid to previous pain episodes, pain reports from various locations on the body, tender points, distress, somatisation, fatigue, and sleep disturbances. Presence of these symptoms may predict development of chronic pain $(8,9)$.

The development and persistence of chronic musculoskeletal pain may also be predicted by several socio-demographic, lifestyle and psychosocial risk factors.

Family history of chronic pain, low educational level, low socioeconomic group and lack of social support are other common risk factors.

Some ethic groups and immigrants have also been shown to have an increased risk for development of chronic pain (11).

Smoking, sedentary lifestyle and obesity are predictive factors that could be targets for intervention (12).

A number of stressors have been temporally correlated with the onset of the syndrome, including trauma, infection (e.g., hepatitis C virus, HIV, Lyme disease), emotional stress, catastrophic events (e.g., war), autoimmune diseases and other pain conditions $(13,14)$.

In conclusion, the goal of secondary prevention is to facilitate early detection of disease development when patients are asymptomatic and intervention improves outcome. Early detection methods for FM patients include analysis of tender points, Fibromyalgia Impact Questionnaire (FIQ), pain location and intensity, fatigue and sleep complaints $(15,16)$.

\section{Tertiary prevention of fibromyalgia}

Tertiary prevention inhibits further deterioration or reduces complications after the disease has declared itself. In FM the aim of treatment is to manage symptoms, specifically, to decrease pain and increase function, via multimodal therapeutic strategies, which, in most cases, include pharmacological and non-pharmacological interventions (17, 18). As FM patients typically present with complex symptoms and co-morbid conditions, they cannot be managed realistically by primary care providers, alone, but require the assistance of multidisciplinary teams with expertise in a variety of physical, cognitive, behavioural and educational strategies (17).

In conclusion, prevention strategies for FM may be of paramount importance. In fact, since no cure is currently available, primary and secondary prevention strategies may greatly reduce the preva- lence of this syndrome. Tertiary prevention will enable patients to implement therapeutic approaches as early as possible, to monitor the results and to prevent the secondary effects of chronic widespread pain and the ancillary symptoms.

\section{The economic impact of fibromyalgia}

Few studies have analyzed the economic impact of FM in terms of costs of disease and pharmacoeconomic balance.

A literature search using keywords "Fibromyalgia" and "Costs and Cost Analysis" identified only 51 publications; of these, only 9 addressed pharmacoeconomic aspects (19-27) and 8 addressed disease costs both as direct costs, i.e., charged to public health systems and to patients for diagnosis and medical assistance, and as indirect costs, i.e., financial consequences of reduced productivity by ill patients (28-35). No publications analyzed the cost or consequence of reduced quality of life for patients.

Over the last decade, the annual direct costs of FM have increased considerably. Today, these costs range between 4.500 and $7.500 €$ per patient (28$35)$. The variability in this range is due to different methods being used to evaluate costs in different years and in different socio-economic conditions of FM patients. The same study, however, concludes that the most important determinant of costs are comorbidities, subjective and objective health state, emotional state and social conditions of the patient $(21,24,28)$.

Health costs comprise about $1 / 3$ of direct costs, a proportion that is accompanied by several causes for concern. First, the cost of admission to the hospital for diagnosis can have a significant impact on overall costs due to the complexity of the clinical symptoms.

Second, therapy can be quite expensive given the overall poor response to treatment among many patients $(31,32,35)$. The lack of validated therapeutic protocols may explain the frequent use of physiotherapy or alternative therapy without a corresponding increase in costs for the public health system (26).

Social support, whether support groups or personal networks, and education programs are inexpensive and useful avenues for facilitating psychological well being and optimizing available health resources (23).

The indirect costs of FM range between 2.000 to $7.000 €$ per patient per year. Only one of three economic studies in our search indicated that the 
indirect costs of FM were higher than the direct costs, as is generally the case for other rheumatic diseases $(31,32,35)$.

If the body of literature for disease costs seems insufficient for FM, the pharmacoeconomic literature is even more inadequate. The majority of these studies have described the methodology of investigation rather than analysed the specific expenses (19-25). Conclusions are not definitive and it is not possible to define the best investment. The justification for this is that well-defined indicators for evaluating achievement of predetermined goals or validated therapeutic protocols were not available. Further, improvements from a specific therapy were too short-lived to draw meaningful conclusions $(23,26,27)$.

\section{Disability and employment in FM patients}

It is difficult to assess disability and employment in FM patients, given the limited data in the scientific literature. Every social assessment is closely related to the socio-economic level of the general population and to the legislation of the country in which the FM patient lives.

In clinical investigations, FM is well known and studied; the case worker, however, is accustomed to evaluating laboratory and physical data objectively and may have reasonable doubts in evaluating the FM patient for insurance purposes and ability to work.

Therefore, it is understandable that there may be fundamental differences in the assessment of disability and employment between Italy and other countries, just as it is understandable that there may be differences between the clinical and medical-legal evaluation of FM patients.

Several difficult issues cloud the ability to estimate the effect of FM in Italy with accuracy. The first issue is the fundamental recognition of disease: Is FM universally recognized by physicians or is it identified with other diseases? How many diagnoses of osteoarthtritis (OA) or how many depressive syndromes or cases of "early arthritis" overlap with FM in clinical practice?

The second issue is the comparison of statistical data. In Italy, it is difficult to compare data from centralized databases that are involved in different aspects of public health: ISTAT (Central Statistic Institute) (36), Ministry of Health, INPS (National Institute of Social Insurance) (37), INAIL (National Board for the Insurance against Accidents in Industrial Work, responsible for occupational diseases) (38).
The ISTAT manages data from sample surveys regarding the influence of chronic diseases; and it suggested the atypical classification of "osteoarthritis-arthritis" that combines diseases which are substantially different. FM has no place in this classification despite its significant incidence among rheumatic diseases and chronic diseases. This incidence of FM has been reported in Italian clinical studies and has been confirmed in the international scientific literature.

INPS and INAIL do not include FM in their statistical data concerning the granting of partial and total disability as paid by the two larger Italian public insurance institutes.

In 1980, the International Classification of Impairments (ICF), Disability and Health (ICDH) included distinctions between impairment, disability and handicap. In 2001, a new International Classification of Functioning (ICF), Disability and Health was officially endorsed by 191 World Health Organization Member States during the 54th World Health Assembly as "the international standard to describe and measure health and disability" (38). The general aim of ICF is to develop a common metric system to describe and measure individual health conditions and contextual factors, which are described by physical, individual, and social perspectives and divided into Functions, Bodily Structures, Participation and Activity. Furthermore, the classification accounts for the environmental factors that can impact the individual's life and interact to determine disability, and it is defined as the consequence or the result of a complex relationship between the health conditions, personal factors and environmental factors representing the circumstances where the individual lives. ICF does not simply view disability only as a "medical" or "biological" dysfunction; rather, it provides a mechanism to document the impact of the social and physical environment on a person's functioning.

The clinical evaluation of disability involves specific assessments such as the FIQ (40), which has been validated in Italy (15). Nevertheless, it is difficult to apply this and other evaluations in legal medicine, especially if they do not refer to laboratory data. Then the claim of disability can lead to additional difficulty for the FM patient if she experiences negative feedback from official Institutions that may not recognize the illness.

Aside from chronic pain, the FM patient may complain of various, specific symptoms that may reduce work performance of the subject. For exam- 
ple, weakness and susceptibility to fatigue are significant in manual laborers, morning stiffness in subjects who begin working early in the morning, such as farm workers, can be debilitating to their livelihood; Raynaud phenomenon can pose severe challenges to operators who are exposed to sudden changes of temperature. Patients who work in external environments can be severely affected by many weather elements such as wind, cold, and rain. Several epidemiological surveys performed in recent years in Great Britain and in Scandinavia demonstrated that FM is greatly disabling and may lead to early termination of employment, regardless of whether this was voluntary or dictated by a medical-legal decision.

In Italy, FM is not recognized as a disabling illness by Insurance Disability (ID), Pensionable Disability (INPS) or Accident or Professional Illness (INAIL). FM is not listed in the ID table of accepted illnesses; therefore, the clinician or medical examiner may refer only to illnesses that are, in a sense, "equivalent" to FM and are included in the assessment table such depressive syndrome and anxiety, or neurosis with varying degrees of severity. It is necessary to indicate comorbidity among illnesses (e.g., FM with anxious syndrome or depressive syndrome).

The same is true in INPS Pensionable Disability, although it must be said that this social Institute grants hydrotherapy for extra-articular rheumatic diseases, including FM. With regard to hydrotherapy we notice that INPS is granted to regular entitled workers as a prevention of pensionable disability and not as non-pharmacologic therapy. In INAIL, FM is not recognized as an industrial injury or an occupational disease, and hydrotherapy is not granted.

For some years, however, INAIL has given special attention to working musculoskeletal disorders (WMSD) that developed from both "heavier" labor, as the manual handling of cargo, and "lighter" labor, as the poor posture or repetitive movement (RSI Repetitive Strain injury) of assembly line workers, monitor operators, check-out clerks (see Legge 626/94 Title V).

In INAIL it would be useful to compare WMSD in a population that is not affected by FM versus FM patients in whom it has been reported that symptoms often get worse as a result of having bad posture or disregarding ergonomics rules. Visitors to the institutional INAIL site can download a useful guide for WMSD (41). The next evaluation of disability and employment in FM could target differ-
Table II - Web hits from a search of the following terms and search engines conducted on 12/02/08.

Google (Italian pages)

Osteoarthritis 226.000

Early arthritis 1.900

Fibromyalgia 30.600

Tendinitis 17.600

Disability 778.000

INAIL (Internal internet search)

Osteoarthritis 14

Rheumatoid arthritis 1

Fibromyalgia 0

Tendinitis 15

Disability 126

INPS (Internal internet search)

Osteoarthritis 3

Early arthritis 0

Fibromyalgia 0

Tendinitis 0

Disability 1079

ent populations such as housewives and students, too (42).

A final consideration, which is also a concrete, positive issue, comes from the Main Office in Health Plan of Ministry of Health contemplated the proposed inclusion of FM in Decree 329799 on chronic disease, as a result of the criteria provided by Decree 124/98 (severity, chronicity and economic burden). It could be a first step towards a new approach to the medico-legal evaluation of FM.

Table II lists web data with regard to the number of hits from various search engines using certain terms from this chapter; web search dated 12/02/08.

\section{Patient associations, mass media and internet}

Although fibromyalgia is a reasonably common clinical condition, it is often left undiagnosed. Unfortunately, this syndrome is not well known to the general practitioner or to physicians, in general.

Many patients have suggested the diagnosis to their doctor after they have discovered the syndrome on the internet or after the reading about it in magazines or newspapers.

Prior to diagnosis, FM patients will often undergo many specialist consultations, laboratory examinations, instrumental examinations and pharmacologic therapies.

Patients are often frustrated by the lack of diagnosis and the meager credibility that physicians and other family members assign to symptoms. Often, 
self-assessment loses its credibility for patients who face disbelief from others and quickly become vulnerable to depression.

In such cases, the satisfaction of a clear diagnosis begins as relief from the fear of an occult neoplasia, but evolves to anger for the unnecessary time spent researching this easy diagnosis, for the money spent without benefit and, finally, for the lack of recognition of this disease.

This aspect, in particular, gives patients a strong motivation to participate in organized volunteer associations.

Voluntary participation in patient associations is not only a social obligation to encourage acknowledgement of FM but also a new social endeavor with a substantial therapeutic benefit.

\section{Patient Associations}

The primary mission of patient associations is to defend patient rights. The main entities to address are governing medical Institutions (Ministry of the Health, regional Councillor of the Health, Local Health Committee, Hospital Committee and Rheumatology Units), and the main goal is to gain acknowledgment of FM as a clinical entity and as a rheumatic disease (43). A search of the Ministry of Health website of using the terms, "fibromyalgia" or "fibromyalgic" did not yield any results. At present, the only region that recognizes FM is the Trentino-Alto Adige.

The main request that FM patient associations have for the Institutions includes exemption for expenses for pathology, the specialized consultations necessary for diagnosis, for follow-up and monitoring, for rehabilitation and for the purchase of specific drugs.

From Rheumatologists, patient associations request specific outpatient activity for FM patients and coordination of other professional specialists that are beneficial to the care of the FM patient, in particular, psychologists and physiotherapists. Patient associations may also provide information to physicians and to the public. They may also request that in-depth study of FM be provided in Rheumatology and Internal Medicine courses at the University.

The Associations promote collaboration between rheumatologists, general practitioners and other specialists for the early diagnosis of FM, which can be achieved via regular meetings sponsored the by Local Health Committee. For easy admittance to gymnasiums and pools for patients to participate in aerobic exercise programs $(44,45)$, participation of the Local Sport Committee is important. Patient associations monitor information on the internet to protect patients against speculative or incorrect information.

The fundamental solidarity of patient associations promotes the sense of community and connection among patients. Patient associations promote local meetings and also take advantage of electronic media, like chat rooms, discussion forums and selfhelp group training (46).

To consolidate their power, FM patients may consider themselves as rheumatic patients and coordinate their voluntary associations with the national associations of rheumatic patients; for example, The Italian Association of FM is supported by the National Association of Rheumatic Patients and by the Italian Rheumatology Society.

\section{Internet and Media}

One of the most significant examples of coordination of information, research, care and voluntary association came from the USA.

The ACR website offers information both to doctors and to patients (47); and it highlights the Rheumatology Units and the Rheumatologists of reference along with links to the principal patient associations $(48,49)$ and the National Institute of Health (NIH). In this virtual strategy, the ACR informs the medical, scientific and public communities about scientific progress; the NIH manages and funds research projects; and the associations help patients through community initiatives, public awareness and collection of resources for research (50).

This example is not followed in Italy, however; with the exception of Rheumatology Units' websites and the official Italian Association of Fibromyalgia Syndrome (51), where scientific information is available without taking advantage of the patient news, we can find news that is without scientific merit, is exaggerated or is directed at selling products without regulatory oversight. People who suffer from an illness often believe in miraculous cures (e.g., surgical or other alternatives to drugs) that are not supported with any scientific validity.

Scientific societies and patient associations are watchful and denounce deceptive publicity of such treatments, but an official medical effort is necessary to control or monitor nonconventional medicines that may be useful for FM patients. It is important to encourage Rheumatology Units to consider meditation techniques and complementary 
treatments derived from traditional Chinese medicine or from other disciplines.

Finally, a website developed by Dr. Weiss (52) provides interesting, evidence-based, accepted information for FM patients This site provides a video of exercise and muscle relaxation techniques that patients can learn and use at home on TV; in addition, the site provides evidence for the positive effects crio-therapy on pain perception in FM patients.

\section{CONCLUSION}

Prevention may occur in clinical, community or population settings and is often classified into primary, secondary and tertiary types. Few studies have analyzed the economic impact of FM in terms of costs of disease and pharmacoeconomic balance. The internet is one of the most significant examples of coordination of information, research, care and voluntary patient advocacy of FM.

\section{SUMMARY}

There many open questions concerning the concept of primary prevention in FM. Diagnostic or classification criteria are not universally accepted, and this leads to difficulties in establishing the onset and duration of the disease. In the case of FM, primary prevention may consist of the immediate care of acute pain or treatment for affective disturbances as we do not have any specific laboratory or instrumental tests to determine risk factors of the disease. The goal of secondary prevention is early detection of the disease when patients are largely asymptomatic and intervention improves outcome. Screening allows for identification of an unrecognized disease or risk factor, which, for potential FM patients, includes analysis of tender points, Fibromyalgia Impact Questionnaire (FIQ), pain location and intensity, and fatigue and sleep complaints. Tertiary prevention inhibits further deterioration or reduces complications after the disease has developed. In FM the aim of treatment is to decrease pain and increase function via multimodal therapeutic strategies, which, in most cases, includes pharmacological and non-pharmacological interventions. Patients with FM are high consumers of health care services, and FM is associated with significant productivity-related costs. The degree of disability and the number of comorbidities are strongly associated with costs. An earlier diagnosis of FM can reduce referral costs and investigations, thus, leading to a net savings for the health care sector. However, every social assessment is closely related to the socio-economic level of the general population and to the legislation of the country in which the FM patient resides.

Key words - Prevention, economic aspects, screening, disability.

Parole chiave - Prevenzione, aspetti economici, screening, disabilità.

\section{REFERENCES}

1. Hauser W, Zimer C, Felde E, Kollner V. What are the key symptoms of fibromyalgia? Results of a survey of the German Fibromyalgia Association. Schmerz 2007.

2. Buskila D, Sarzi-Puttini P. Biology and therapy of fibromyalgia. Genetic aspects of fibromyalgia syndrome. Arthtritis Res Ter 2006; 8: 218.

3. Martinez-Lavin M. Biology and therapy of fibromyalgia. Stress, the stress response system and fibromyagia. Arthtritis Res Ther 2007; 9: 216.

4. Wolfe F, Smythe HA, Yunus MB, Bennett RM, Bombardier C, Goldenberg DL, et al. The American College of Rheumatology 1990 criteria for the classification of fibromyalgia: report of a multicenter criteria committee. Artrhritis Rheum1990; 33: 160-72.

5. Mease P. Fibromyalgia syndrome: review of clinical presentation, pathogenesis, outcome measures and treatment. J Rheumatol 2005; 75: 6-21.

6. Webb R, Bramah T, Lunt M, Urwin M, Allison T, Symmons D. Prevalence and predictors of intense, chronic and disabling neck and back pain in the UK general population Spine 2003; 28: 1195-202.

7. Rao JK, Hootman JM. Prevention research and rheu- matic disease. Curr Opin Rheumatol 2004; 16: 119-24.

8. Gieseke T, Gracely RH, Willams DA, Geisser ME, Petzke FW, Clauw DJ. The relationship between depression, clinical pain and experimental pain in chronic pain cohort. Arthritis Rheum 2005; 52: 1574-84.

9. Theorell T, Harms-Ringdahl K, Ahlberg-Hulten G, Westin B. Psycosocial job factors and symptoms from the locomotor system-a multicausal analysis. Scand J Rehabil Med 1991; 23: 165-73.

10. McBeth J, Macfarlane GJ, Hunt IM, Silman AJ. Risk factors for persisten chronic widespread pain: a community-based study Rheumatology (Oxford) 2001; 40: 95-101.

11. Allison TR, Symmons DP, Brammah T, Haynes P, Rogers A, Roxby M, et al. Muscoloskeletal pain is more generalised among people from ethnic minorities than among white people in Greather Manchester. Ann Rheum Dis 2002; 61: 151-6.

12. Goldberg MS, Scott SC, Mayo NE. A review of the association between cigarette smoking and the development of non specific back pain and related outcomes Spine 200; 25: 995-1014.

13. Walker-Bone K, Cooper C. Hard work never hurt anyone: or did it? A review of occupational associations 
with soft tissue musculoskeletal disorders of the neck and upper limb. Ann Rheum Dis 205; 64:1391-6.

14. Bazzichi L, Rossi A, Giuliano T, De Feo F, Giacomelli C, Consensi A, el al. Association between thyroid autoimmunity and fibromyalgic disease severity. Clin Rheumatol 2007; 26: 2115-20.

15. Sarzi-Puttini P, Atzeni F, Turiel M, Furlan R, Vulpio L, Carrabba M, Pace F. The Italian version of the Fibrofatigue Scale, a reliable tool for the evaluation of fibromyalgia sympoms. J Psychosom Res 2004; 56: 21316.

16. Sarzi-Puttini P, Atzeni F, Fiorini T, Panni B, Randisi $\mathrm{G}$, Turiel M, et al. Validation of an Italia version of the Fibromyalgia Impact Questionnaire (FIQ-1) Clin Exp Rheumatol 2003; 21: 459-64.

17. Sarzi-Puttini P, Buskila D, Carrabba M, Doria A, Atzeni F. Treatment strategy in Fibromylgia Sindrome: where are we now? Semin. Arthritis Rheum 2008; 37: 353-65.

18. Cazzola M, Sarzi-Puttini P, Buskila D, Atzeni F. Pharmacological treatment of fibromyalgia. Reumatismo 2007; 59: 280-91.

19. McCain GA. A cost-effective approach to the diagnosis and treatment of fibromyalgia. Rheum Dis Clin North Am 1996; 22; 323-49.

20. Goossens ME, Rutten-van Molken MP, Vlaeyn JW, van der Linden SM. The cost diary: a method to measure direct and indirect costs in cost-effectiveness research. J Clin Epidemiol 2000; 53: 688-95.

21. Walen HR, Cronan PA, Bibatti SM. Factors associated with healthcare costs in women with fibromyalgia. Am J Manag Care 2001; 25: 39-47.

22. Oliver K,Cronan TA, Walen HR Tomita M. Effects of social support and education on health care costs for patients with fibromyalgia J Rheumatol 2001; 28: 2711-9.

23. Pfeiffer A, Thompson JM, Nelson A, Tuker S, Luedkte C, Finnie S, et al. Effects of a 1.5 day multidisciplinary outpatient treatment program for fibromyalgia: a pilot study Am J Phys Med. Rehabil 2003; 82: 186-91.

24. Buesing AR A conservative, cost-effective approach to fibromyalgia JAAPA 2005; 18: 32-7.

25. Ribinson RL, Jones ML. In search of pharmacoeconomic evaluations fof fibromyalgia treatments: a review Expert Opin Pharmacother 2006; 7: 1027-39.

26. Lind BK, Lafferty WE, Tyree PT, Diehr PK, Grembowski DE. Use of complementary and alternative medicine providers by fibromyalgia patients under insurance coverage Arthritis Rheum 2007; 57: 71-6.

27. Zijlstra TR Braakman-Jansen LM, Taal E, Rasker JJ, van der Laar MA. Cost-effectiveness of Spa treatment for fibromyalgia: general health improvement is not for free Rheumatology 2007; 46: 1454-59.

28. Wolfe F, Anderson J, Harkness D, Bennett RM, Caro XJ, Goldenberg DL, et al. A prospective, longitudinal, multicentric study on service utilization and costs in fibromyalgia. Arthritis Rheum 1997; 40: 1560-70.

29. With KP, Speechley M, Harth M,Ostbye T. The London Fibromyalgia Epidemiology Study: direct health care costs of fibromyalgia syndrome in London, Canada J Rheumatol 1999; 26: 885-9.
30. Robinson RL, Bimbaum HG, Morley MA, Sisitsky T, Greenberg PE, Claxton AJ. Economic cost and epidemiological characteristics of patients with fibromyalgia claims J Rheumatol 2003; 30: 1318-25.

31. Penrod JR, Bernatsky S, Adam V, Baron M, Dayan N, Dobkin PL. Healh services costs and their detrminats in women with fibromyalgia J Rheumatol 2004; 31 : 1391-8.

32. Boonen A, van den Heuvel L, van Tubergen A, Goosens M, Severens J1, van der Heijde D, et al. Large differences in cost of illness and well being between patients with fibromyalgia, chronic low back pain or ankylosing spondylitis Ann Rheum Dis 2005; 64: 396402.

33. Robinson RL, Bimbauem HG, Morley MA, Sisitsky T, Greeberg PE, Wolfe F. Depression and fibromyalgia: treatment and cost when diagnosed separately or concurrently. J Rheumatol 2004; 31: 1621-9.

34. Berger A, Dukes E, Martin S, Edelsberg J, Oster G. Characteristics and healthcare costs of patients with fibromyalgia syndrome Int J Clin Pract 2007; 61: 1498508.

35. With LA, Bimbaum HG, Kaltenboeck A, Tang J, Mallett D, Robinson RL. Employees with fibromyalgia; medical comorbidity, healthcare costs and work loss. Occup Environ Med 2008; 50: 13-24.

36. www.istat.it

37. www.inps.it

38. www.inail.it

39. www.disabilitaincifre.it

40. Burkhardt C, Clark SR, Bennet RM. The Fibromyalgia Impact Questionnaire: development and validation. J Rheumatol 1991;18: 728-33.

41. Marsico A. Malattie reumatiche : impatto nel mondo del lavoro del 2000. atti del III Congresso Nazionale dei Reumatologi Ospedalieri Terme di Telese (BN) 911 dicembre 1999; 73-8.

42. Gerloni V, Ghirardini M, Fantini F. Assessmnt of non articular tenderness and prevalence of primary fibromyalgia syndrome in healthy Italian schoolchildren. Arthritis Rheum 1998; 41: 1405.

43. Baffigi A, Granata A, Sarzi-Puttini P, et al. Quality of life and mood disturbances in fibromyalgia and irritable bowel syndrome Ann Rheum Dis 2002: 61 (suppl 1); 151.

44. Mannerkorpi K. Exercise in fibromyalgia Curr Opin Rheumatol 2005; 17: 190-4.

45. Rooks DS, Silvermann CB, Kantrowitz FG. The effect of progressive strength training and aerobic exercise on muscle strength and cardiovascular fitness in women with fibromyalgia: a pilot study. Arthritis Rheum 2002; 47: 22-8.

46. www.it.geocities.com/fibroamici2004/

47. www.rheumatology.org/public/factscheets/fibromyanew.asp? aud=pat

48. www.afsafund.org

49. www.fmaware.org/site/PageServer

50. www.fmpartnership.org

51. www.sindromefibromiagica.it

52. www.weiss.de 